\title{
Ameliorative potentials of a combination of fenugreek and alpha-tocopherol on cadmium induced testicular toxicity: an ultrastructural study
}

\author{
A.M. Hussein, H.N. Mustafa, M.H. Badawoud \\ Anatomy Department, Faculty of Medicine, King Abdulaziz University, Jeddah, Saudi Arabia \\ [Received 3 November 2014; Accepted 17 December 2014]
}

Background: The current study aimed to elucidate the protective role of combined fenugreek and $\alpha$-tocopherol against cadmium induced histopathological changes in the testes.

Materials and methods: Thirty adult male albino rats divided into three equal groups 10 rats each. Group I is the control group. Group II received $5 \mathrm{mg} / \mathrm{kg} / \mathrm{day}$ cadmium chloride. Group III received $5 \mathrm{mg} / \mathrm{kg} /$ day cadmium chloride and 150 $\mathrm{mg} / \mathrm{kg} /$ day fenugreek and $100 \mathrm{mg} / \mathrm{kg} /$ day of $\alpha$-tocopherol. The treatment of all groups was done by oral gavage for 60 consecutive days. The testes were removed and subjected to histopathological and ultrastructure study.

Results: Rats exposed to cadmium showed severe histopathological changes in the testicular spermatogenic series, many vacuoles and multinucleated giant cells. Treatment with fenugreek and $\alpha$-tocopherol partially improved the morphological changes, reduced tissue damage and rebuilt of the spermatogonia layer. Conclusions: Fenugreek and $\alpha$-tocopherol might represent a promising medicinal combination to ameliorate the toxic effects of cadmium exposure. (Folia Morphol 2015; 74, 3: 325-334)

Key words: cadmium chloride, fenugreek, $\alpha$-tocopherol, seminiferous epithelium, ultrastructure

\section{INTRODUCTION}

Recently, cadmium has received global interest as an ecological pollutant primarily because of its immensely long biological half-life, so exposure to cadmium still causes toxic effects even after long periods of a cessation of exposure due to its residual effects $[27,49]$.

Cadmium (Cd) is a heavy metal used in paint pigments, nickel-cadmium batteries, plastics, dyes, and electrochemistry. It is found in cigarette smoke, fungicides, insecticides, and commercial fertilizers that are used in agriculture $[17,46] . \mathrm{Cd}$ may cause nephrotoxicity, testicular necrosis, prostatic and testicular cancers, liver damage, cardiovascular diseases, osteoporosis and neurodegenerative conditions [59].

Peroxidation induced by $\mathrm{Cd}$ is the cause of the release of free oxygen radicals [30]. The oxygen radicals lead to the destruction of sensitive molecules and tissues [39]. After exposure to $\mathrm{Cd}$, testicular damage results and can be observed at the interstitial and tubular levels [59]. Permeability alterations in the capillary endothelium, which cause oedema,

Address for correspondence: Dr H.N. Mustafa, MSc, MD, King Abdulaziz University, Faculty of Medicine, Anatomy Department, Building No. 8 - P.O. Box: 80205 Jeddah: 21589 Saudi Arabia, tel: +966 566764 762, e-mail: hesham977@hotmail.com 
haemorrhages and necrosis, appear to be involved in the histopathological mechanism of these lesions [22]. Moreover, it is well known that prolonged $\mathrm{Cd}$ exposure leads to carcinogenic effects on the male reproductive organs [29] and leads to a reduction in reproductive capabilities [48].

Vitamin $E$ is the collective name for a band of fatsoluble substances with unique antioxidant activities that is available in 8 chemical forms $(\alpha-, \beta-, \gamma$ - and $\delta$-tocopherol, $\alpha-, \beta$-, $\gamma$ - and $\delta$-tocotrienol) that have diverse degrees of biologic activity [12]. The chemical form $\alpha$-tocopherol is the most recognised and found in many food items, including nuts, seeds and vegetable oils [21]. The body forms reactive oxygen species (ROS) endogenously which comprise both free radical and non-free radical oxygen such as hydrogen peroxide $\left(\mathrm{H}_{2} \mathrm{O}_{2}\right)$, superoxide (O2-) and hydroxyl radical $(\mathrm{OH})$ [57]. Alpha-tocopherol causes the elimination of the free oxygen radicals and the inhibition of the peroxidation [19]. It acts by eliminating lipid peroxyl and alkoxyl radicals, so it suppresses the chain reaction of lipid peroxidation and promotes the production of scavenger antioxidant enzymes [18].

Numerous reports in several labs are going on to evaluate the preventive influence of different natural substances toward poisonous metals [24]. Fenugreek seed (Trigonella foenum-graecum L. cultivar Baladi, family: Leguminosae) is herb of the Legume family that is broadly grown in Egypt and India. Used with meal as a spice and in medication where it demonstrates antioxidant impact in diabetes mellitus due to the existence of various ingredients $[20,53]$.

The aim of this study is to evaluate the cytoprotective effects of fenugreek and $\alpha$-tocopherol on $\mathrm{Cd}$ chloride induced testicular damage.

\section{MATERIALS AND METHODS}

Ethical approval. This study was conducted after receiving the approval of the Medical Research Ethics Committee, Faculty of Medicine, King Abdulaziz University.

Animals. Thirty male adult Wistar rats aged 120 days that weighed $175-200 \mathrm{~g}$ and were obtained from the animal house were weighed and randomly placed into three groups $(n=10)$. The rats were housed individually in stainless steel cages with controlled temperature $\left(22 \pm 2^{\circ} \mathrm{C}\right)$ and humidity $(55 \pm$ $10 \%$ ) and $12 / 12 \mathrm{~h}$ cycle of light and darkness with access to food and drinking water ad libitum. The experimental procedures were performed in accor- dance with the international guidelines for the care and the use of animals in a laboratory.

Chemicals. Cadmium chloride ( $\mathrm{CdCl}_{2}, 99 \%$ pure) and $\alpha$-tocopherol were purchased from Sigma-Aldrich Chemicals Co. (St. Louis, MO, USA).

Fenugreek powder preparation. Fenugreek (Trigonella foenum-graecum $L$.) was purchased from local herbal market. Fifty grams of fenugreek-dried seeds were crushed, boiled in $1 \mathrm{~L}$ of distilled water for half an hour. Then the extracts were filtered. The powder was mixed at $5 \% \mathrm{w} / \mathrm{w}$ in standard rat pelleted diet (i.e. $5 \mathrm{~g}$ of dry fenugreek in $95 \mathrm{~g}$ of rat food). The dose used in the current work was selected according to a previous research [4]. The chemical constituents of fenugreek are carbohydrate $(49.81 \mathrm{~g} \%)$, protein $(27.31 \mathrm{~g} \%)$, fat $(7.11 \mathrm{~g} \%)$, ash (3.67 g\%), steroidal saponins (2 g\%), flavonoids (399.67 $\mathrm{mg} \%$ ), trigonelline alkaloid (380 $\mathrm{mg} \%$ ) and polyphenols (251.71 $\mathrm{mg} \%$ ) $[4,26]$.

Experimental design. Group I received $1 \mathrm{~mL}$ of normal saline and served as the control group. Group II received $5 \mathrm{mg} / \mathrm{kg} /$ day $\mathrm{CdCl}_{2}$ (1/15 LD50) [43]. Group III received $5 \mathrm{mg} / \mathrm{kg} / \mathrm{day} \mathrm{CdCl}_{2}$ and $150 \mathrm{mg} / \mathrm{kg} /$ day fenugreek and $100 \mathrm{mg} / \mathrm{kg} / \mathrm{day}$ of $\alpha$-tocopherol [6]. The prophylactic combination started 1 week before $\mathrm{CdCl}_{2}$ administration in the current study to acquire the benefits of both curative and preventive regimens. All groups were treated by oral gavage for 60 consecutive days.

Testis histology. At the end of the experiment, the animals were anesthetised, weighed and sacrificed by decapitation. The testes were removed and weighed. Subsequently the testes were fixed in $10 \%$ neutral buffered formalin, processed for $5-\mu \mathrm{m}$ paraffin sections and stained with haematoxylin and eosin (H\&E). For each specimen, at least 3 to 5 slides were examined using an Olympus BX53 microscope equipped with a DP73 digital camera (Olympus, Tokyo, Japan) [34, 38, 54].

Immunohistochemistry. Paraffin sections were de-waxed in xylene, rehydrated and pretreated with $3 \%$ of hydrogen peroxide to block endogenous peroxidase activity. Microwave-assisted antigen retrieval was performed for $20 \mathrm{~min}$. Slides were then incubated overnight at $4^{\circ} \mathrm{C}$ with the primary antibody (Anti CD68+ for macrophages [1:50], Anti CD3 + for T-lymphocytes [1:200] and Anti CD20+ for B-lymphocytes [1:300]) (Rabbit Polyclonal Antibody from Neo-Markers, Lab Vision Corporation) and sections were incubated with biotinylated $\lg G$ and then with streptavidin-peroxidase conjugate (Zymed Corp.). Sec- 
Table 1. Mean testes weight and body weight

\begin{tabular}{lcc}
\hline & Body weight $[\mathrm{g}]$ & Testis weight $[\mathrm{g} / \mathbf{1 0 0} \mathrm{g}]$ \\
\hline Control $(\mathrm{n}=10)$ & $210.40 \pm 3.062$ & $0.73 \pm 0.036$ \\
$\mathrm{CdCl}_{2}(\mathrm{n}=10)$ & $199.5 \pm 0.028^{*}$ & $0.61 \pm 0.084^{*}$ \\
& $\mathrm{P}<0.001$ & $\mathrm{P}<0.001$ \\
Combined fenugreek and $\alpha$-tocopherol & $208.10 \pm 0.994$ & $0.68 \pm 0.030$ \\
with $\mathrm{CdCl}_{2}(\mathrm{n}=10)$ & $\mathrm{P}<0.128$ & $\mathrm{P}<0.139$ \\
\hline
\end{tabular}

*Values are expressed as a mean \pm standard deviation. The analysis was conducted using one-way ANOVA followed by Tukey's post-hoc test.

tions were then washed with phosphate-buffered saline (PBS) and incubated with 3-3' diaminobenzidine tetrachloride (DAB) for 5 min to detect immunoreactivity. Sections were counterstained with haematoxylin. Negative control sections were prepared by omitting the primary antibody. Positive control standard laboratory slides were used for all stains to validate the success of the technique. All slides were examined under light microscopy and the presence of labelled cells was documented. The absence of staining was recognised as a negative result (-) while the presence of brown staining was recognised as a positive result (+) [54].

Morphometry. Five slides of the testes of each group ( 6 fields per slide), seminiferous tubules round or almost round were selected indiscriminately and analysed. The mean seminiferous tubule diameter was obtained by measuring across the minor and major axes. The seminiferous epithelium height was measured for the same tubules. The epithelium height was calculated as the space between the tunica propria and the edge of the lumen and two diametrically opposed readings were taken with a digital ruler on each cross section using their mean value [33]. The measurements were taken at magnifications of $\times 100$ and $\times 200$ using the Image-Pro Plus v6.0 (Media Cybernetics, Maryland, USA) and an Olympus BX53 microscope. In addition, the percentage of the immunopositive cells in the testicular tissue was evaluated.

Ultrastructure study. Testes samples of approximately $1 \mathrm{~mm}^{3}$ were obtained and immersed in $2.5 \%$ of glutaraldehyde in a $0.1 \mathrm{M}$ buffer phosphate at $4^{\circ} \mathrm{C}$ for $3 \mathrm{~h}$ and post-fixed in $1 \%$ of osmium tetraoxide. After dehydration in a graded series of ascending concentrations of ethanol, the tissues were embedded in epon 812. Semithin sections were prepared from the blocks, stained using toluidine blue and observed with the Olympus microscope. Demonstrative areas of semithin sections were chosen. Ultrathin sections of a
50-60 nm of thickness were cut using ultramicrotome (NOVA, LKB 2188, Bromma, Sweden) and uranyl acetate and lead citrate were used to stain the tissues and then inspected using a Philips 201 transmission electron microscope at $60-80 \mathrm{kV}$ in a transmission electron microscope unit (Philips Industries, Eindhoven, Netherlands) [37].

Statistical analysis. Quantitative data were expressed as the mean \pm standard deviation of different parameters for the treated groups. The data were analysed using the one way analysis of variance (ANOVA) after testing Levene's test verified the equality of variances in the samples (homogeneity of variance) ( $p>0.05)$. In the parametric data which equality was assumed we used Tukey's post-hoc test for comparison between variable, meanwhile in parametric parameters in which equality of data were not assumed (CD3, CD20, CD68) we use Dunnett's T3 test for comparison between groups. The statistical analysis was performed using SPSS version 22 . The values were considered significant when $p<0.05$.

\section{RESULTS}

Body and testes weight. Rats received $\mathrm{CdCl}_{2}$ revealed a significant reduction in the body weight and testis weight in comparison with control group. Administration of combined fenugreek and $\alpha$-tocopherol with $\mathrm{CdCl}_{2}$ improved body weight and testes weight (Table 1).

The histological evaluation of the testes of the control group shows the normal architecture of the seminiferous tubules (Fig. $1 \mathrm{~A}$ ). $\mathrm{CdCl}_{2}$ treated group showed disintegration, disorganisation and the loss of the typical cytoarchitecture of the tubules (oval or circular) with a separation of the spermatogonia from the basal lamina, a widening of the interstitial spaces and congestion of the capillaries. Some tubules showed vacuoles of different sizes inside and in between the spermatogenic cells, spermatogenic cells 


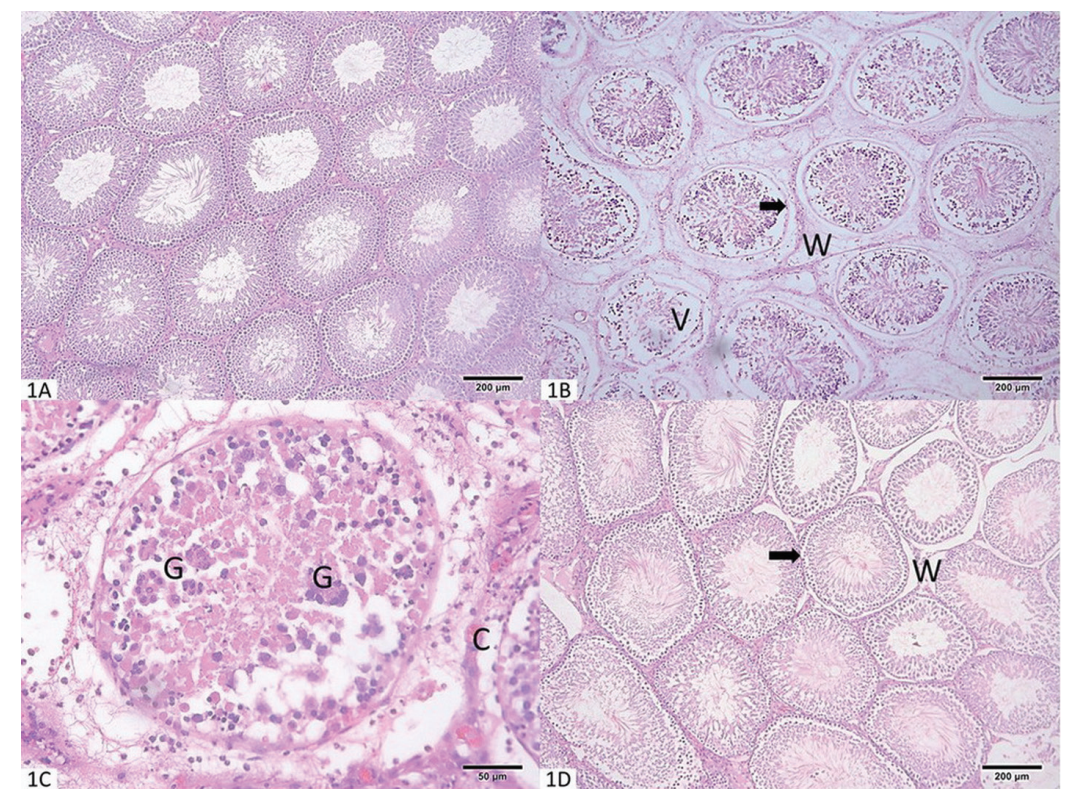

Figure 1. A. Photomicrograph of the control group; B. The group treated with $\mathrm{CdCl}_{2}$ showed vacuolation (V) with spermatogonia separated from the basal lamina ( $\uparrow$ ) and a widening of the interstitial spaces (W); C. Higher magnification showed multinucleated giant cells (G) and congestion of the capillaries (C); $\mathbf{D}$. The group treated with $\mathrm{CdCl}_{2}$ and combined fenugreek and $\alpha$-tocopherol showed restoration of the spermatogonia near the basal lamina ( $\uparrow$ ) and a decrease of the widening (A, B, D scale bar $200 \mu \mathrm{m}$; C scale bar $50 \mu \mathrm{m})$.

sloughed, detached and lost the support of Sertoli cells so they could no longer survive and there was appearance of giant cells with multiple nuclei (Fig. 1B C). Combined fenugreek and $\alpha$-tocopherol with $\mathrm{CdCl}_{2}$ minimised the degenerative changes evidenced by the reappearance of the spermatogonia near the basal lamina as well as the restoration of the structure of the seminiferous tubules and no cavities or vacuoles were detected nearly in all exposed animals (Fig. 1D).

Toluidine blue stained sections. The testes of the control group reveal the typical histological picture of the seminiferous tubules (Fig. 2A). The group treated with $\mathrm{CdCl}_{2}$ showed disorganisation of the seminiferous tubules with an obvious diminution of the epithelial layers, extensive degenerative vacuolisation and intercellular empty spaces in between the cells. Also, the spermatozoa disappeared, the spermatids exfoliated, the primary spermatocytes' density was diminished and the spermatogonia noticeably deteriorated and depleted (Fig. 2B, C). Combined fenugreek and $\alpha$-tocopherol with $\mathrm{CdCl}_{2}$ showed an apparent improvement of the architecture of the seminiferous tubules with a partial restoration of a low germinal epithelium more or less in all exposed animals and minimal or no vacuolations among the germ cells (Fig. 2D, E).

Morphometric analysis. The mean seminiferous tubular diameter showed variations in the different groups in comparison with the control group. The data showed that there was a significant decrease in the mean diameter of the seminiferous tubules in the $\mathrm{CdCl}_{2}$ treated group in comparison with the control group, however there was an improvement in the diameter of the seminiferous tubules of the group treated with combined fenugreek and $\alpha$-tocopherol and $\mathrm{CdCl}_{2}$. The mean germin:al epithelial height of the $\mathrm{CdCl}_{2}$ treated group showed a significant decrease in comparison with the control group. The group treated with $\mathrm{CdCl}_{2}$ and combined fenugreek and $\alpha$-tocopherol showed significant improvement in the epithelial heights (Table 2).

Immunohistochemistry study. The data showed that there were significant increases in the area percentage of $\mathrm{CD} 3, \mathrm{CD} 20$ and $\mathrm{CD} 68$ in the $\mathrm{CdCl}_{2}$ treated group in comparison with the control group (Table 3).

Ultrastructure picture. The transmission electron micrographs of the control group reveal a normal structural organisation of the seminiferous tubules and the interstitium. The $\mathrm{CdCl}_{2}$-treated testes revealed several vacuoles of variable sizes inside and in between the germ cells and an apparently thickened basal lamina with a myoid cell. Sertoli cells with an irregular euchromatic nucleus and the characteristic indentation of the nucleus resting on the basal lamina with numerous vacuoles and an increase in the density of the cytoplasmic inclusions, also unhealthy damaged cells were observed. The primary spermato- 


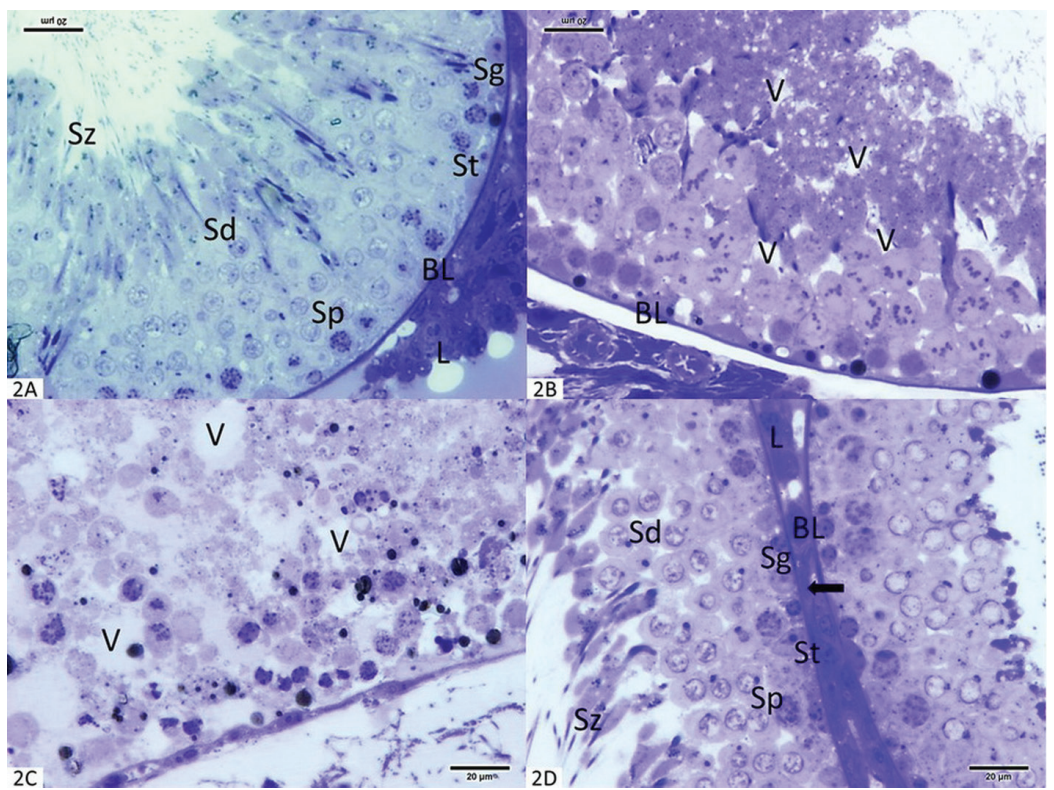

Figure 2. Photomicrograph of a semithin section of a testis of a rat; A. Control group. Note: Sertoli cells (St), Spermatogonia (Sg), basal lamina (BL), spermatocytes (Sp), spermatid (Sd), spermatozoa (Sz); B. The group treated with $\mathrm{CdCl}_{2}$ showed vacuolations (V); C. Depletion, extensive vacuolisation (V) of the germinal epithelium; $\mathbf{D}$. The group treated with $\mathrm{CdCl}_{2}$ and combined fenugreek and $\alpha$-tocopherol with $\mathrm{CdCl}_{2}$ showed improvement of the epithelial layers. Note: myoid cell ( $\uparrow$ ), interstitial Leydig cells (L) (Scale bar $20 \mu \mathrm{m}$ ).

Table 2. Mean diameter of seminiferous tubules (MSTD) and germinal epithelial height

\begin{tabular}{lccc}
\hline & $\begin{array}{c}\text { Control } \\
(\mathbf{n}=\mathbf{2 0 0})\end{array}$ & $\begin{array}{c}\mathbf{C d C l}_{2} \\
(\mathbf{n}=\mathbf{2 0 0})\end{array}$ & $\begin{array}{c}\text { Combined fenugreek and } \\
\alpha \text {-tocopherol (n= 200) }\end{array}$ \\
\hline Tubular diameter (MSTD) $[\mu \mathrm{m}]$ & $253.427 \pm 17.536$ & $240.256 \pm 29.926$ & $246.223 \pm 34.145$ \\
& & $\mathrm{P}<0.0001^{*}$ & $\mathrm{P}<0.029^{*}$ \\
Seminiferous epithelium height $[\mu \mathrm{m}]$ & $76.502 \pm 5.549$ & $70.066 \pm 8.319$ & $73.333 \pm 7.962$ \\
& & $\mathrm{P}<0.0001^{*}$ & $\mathrm{P}<0.0001^{*}$ \\
\hline
\end{tabular}

*Values are expressed as a mean \pm standard deviation. The analysis was conducted using one-way ANOVA followed by Tukey's post-hoc test.

Table 3. Mean area percentage of CD3, CD20, and CD68 immunostaining

\begin{tabular}{|c|c|c|c|}
\hline Area \% & $\begin{array}{l}\text { Control } \\
(\mathrm{n}=10)\end{array}$ & $\begin{array}{c}\mathrm{CdCl}_{2} \\
(\mathrm{n}=10)\end{array}$ & $\begin{array}{l}\text { Combined fenugreek and } \\
\alpha \text {-tocopherol }(\mathbf{n}=10)\end{array}$ \\
\hline \multirow[t]{2}{*}{ CD3 } & $0.031 \pm 0.027$ & $0.090 \pm 0.049$ & $0.056 \pm 0.060$ \\
\hline & & $P<0.014^{*}$ & $P<0.553$ \\
\hline \multirow[t]{2}{*}{ CD20 } & $0.050 \pm 0.022$ & $0.091 \pm 0.040$ & $0.060 \pm 0.026$ \\
\hline & & $P<0.033^{*}$ & $P<0.692$ \\
\hline \multirow[t]{2}{*}{ CD68 } & $0.058 \pm 0.028$ & $0.139 \pm 0.080$ & $0.106 \pm 0.073$ \\
\hline & & $P<0.034^{*}$ & $P<0.213$ \\
\hline
\end{tabular}

*Values are expressed as a mean \pm standard deviation. The analysis was conducted using one-way ANOVA followed by Dunnett's T3 test post-hoc test.

cytes with disrupted chromatin are separated by the variable sizes of the intercellular spaces and the vacuolated distorted mitochondria. In addition, several vacuoles of variable sizes all over the cytoplasm were observed. Mid-piece of the sperm with distorted and swollen mitochondrial sheaths surrounds the central axoneme. Spermatids with rounded or oval nuclei that have disturbed chromatin and peripherally arranged 


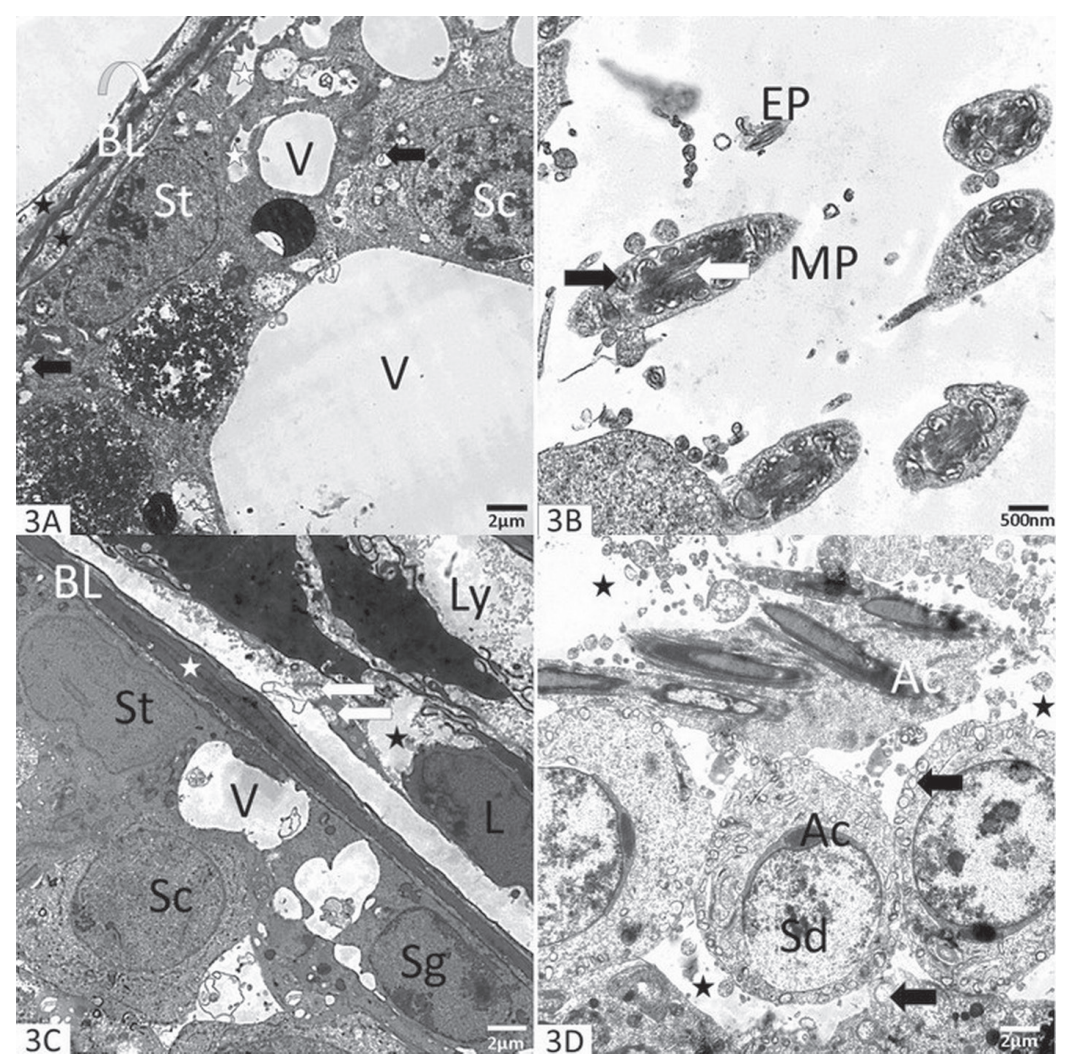

Figure 3. An electron micrograph of a testis of the $\mathrm{CdCl}_{2}$ treated group; $\mathbf{A}$. Sertoli cell ( $\mathrm{St}$ ) and primary spermatocyte $(\mathrm{Sc}$ ) is separated by spaces (white star) and vacuolated mitochondria (black arrows). Vacuoles (V) and thickened basal lamina (BL) containing collagen (black star) and a myoid cell (curved arrow); B. Mid-piece of the sperm (MP) with swollen mitochondria (black arrow) surrounds the central axoneme (white arrow). Note: End pieces (EP); C. Leydig cell (L), vacuoles (V), an empty space (black star), lymph vessels (Ly) and vacuolated mitochondria (white arrow). The spermatogonia $(\mathrm{Sg})$ and the Sertoli cell (St) and thickened basal lamina (BL) with a myoid cell (white star), primary spermatocyte (Sc); D. Spermatids (Sd) with mitochondria with lost cristae (black arrow) and acrosomal cap (Ac). Empty spaces (black star) are all around (A, C, D scale bar $2 \mu \mathrm{m}$; B scale bar $500 \mathrm{~nm}$ ).

the mitochondria with lost cristae and acrosomal cap. Leydig cells with oval, indented nuclei with disrupted chromatin are noticed and apparent electron dense bodies, vacuoles, empty spaces, lymph vessels and ruptured vacuolated mitochondria. Unhealthy cells characterised by heterochromatin condensation and shrinkage of both cytoplasm and nucleus, which is an indication of phagocytosis (Fig. 3A-D).

While the recovery group showed minimal vacuolation, some mitochondria were still affected and others are healthy mid pieces of the sperm were nearly improved and restored nearly in all exposed animals. Reconstruction of the structure of the crosssections of the mid pieces with axoneme surrounded by a mitochondrial sheath is noticed. Leydig cells with oval euchromatic nuclei and peripherally located heterochromatin. The cytoplasm contains multiple lysosomes. Improvement of the appearance of germ cells is observed. The Spermatids with rounded or oval euchromatic nuclei and peripherally arranged mitochondria with preserved cristae and acrosomal cap were observed. Minimal empty spaces in the affected intercellular bridge are still noticed (Fig. 4A-D).

\section{DISCUSSION}

Cadmium is a poisonous heavy metal that is attributed to it reduced elimination rate [51]. Male genital organs are obviously affected during environmental exposure to $\mathrm{Cd}$ as proved by bad quality of seminal fluid and sterility [7]. In the current study, it is observed that administration of $\mathrm{CdCl}_{2}$ lowered testicular weight and body weight and this is related to reduced androgen level [52]. Moreover, $\mathrm{CdCl}_{2}$ decreases total sperm count and raises anomalous sperm forms [35] and induces necrotic destruction of testicular tissues [25]. In addition, the undifferentiated spermatogenic cell count is declined [40].

With light microscopic examination, $\mathrm{CdCl}_{2}$ treated group showed degenerative alterations in the testicular histology with damage of the supporting cells of Sertoli that ultimately causes irreversible loss and detachments of spermatogonia and this agreed with 


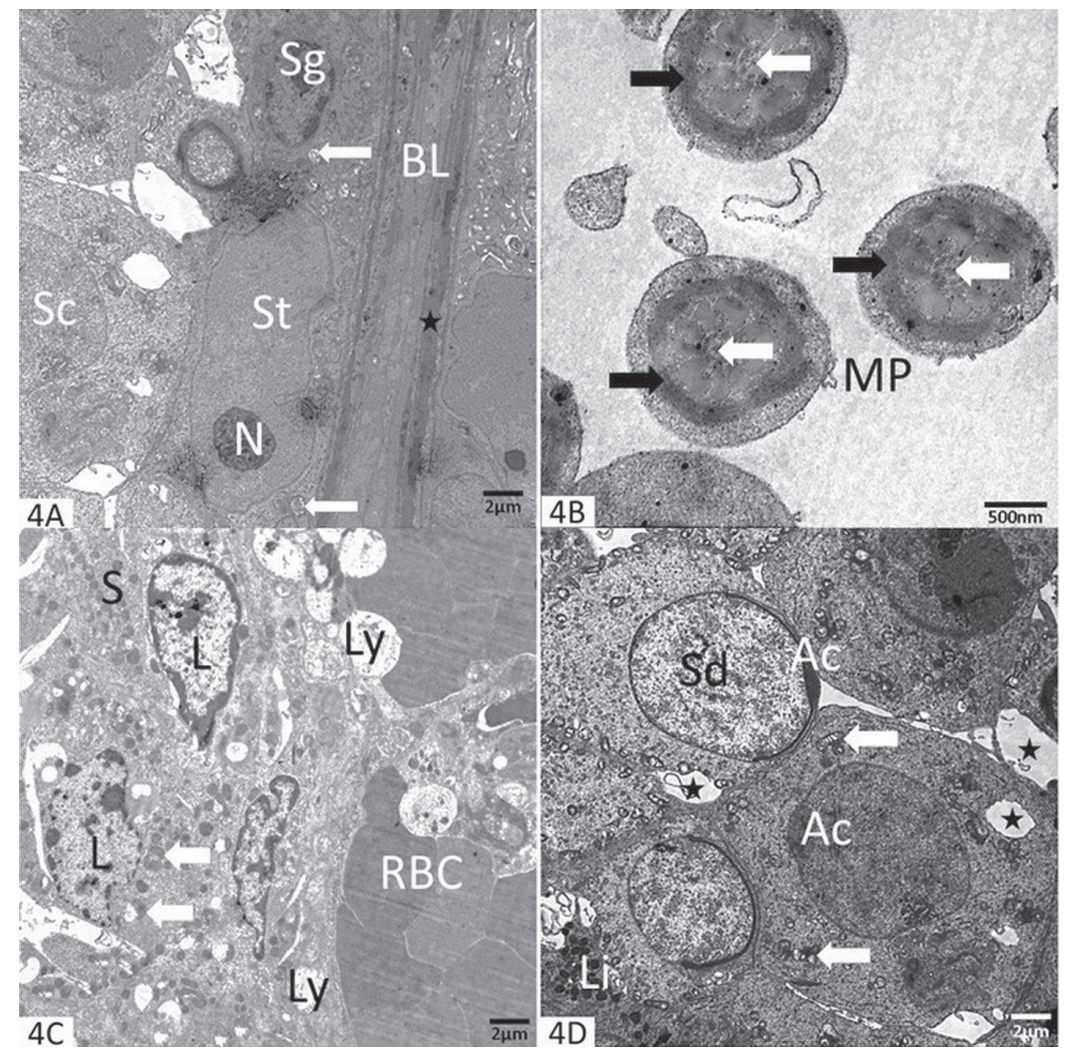

Figure 4. An electron micrograph of a testis from group treated with combined fenugreek and $\alpha$-tocopherol and $\mathrm{CdCl}_{2} ; \mathbf{A}$. Sertoli cell (St) with a nucleolus $(\mathrm{N})$ and the spermatogonia $(\mathrm{Sg})$ on the thickened basal lamina $(\mathrm{BL})$ with myoid cell (black star). Mitochondria (arrow) and primary spermatocyte (Sc) noticed; B. Mid-pieces (MP) with axoneme (white arrow) and a mitochondrial sheath (black arrow); C. Leydig cells (L), multiple lysosomes (S) and mitochondria (arrow) and Lymph vessels (Ly); D. The Spermatids (Sd) with mitochondria with preserved cristae (arrow) and acrosomal cap (Ac). Minimal empty spaces (star) in the affected intercellular bridge and lipid droplets (Li) (A, C, D scale bar $2 \mu \mathrm{m}$; B scale bar $500 \mathrm{~nm})$.

a previous research [58]. Morel et al. [36] found that Leydig cells' morphology is altered with disrupted chromatin followed by reduction in the cell number and is irreversibly substituted by inflammatory cells and this agreed with the current findings that are supported by the immunomarkers increased expression. It is noted that fenugreek consumption restored serum testosterone level and testicular weight [45]. The fenugreek being an antioxidant, it performs a crucial role in restoring testosterone level by eliminating ROS which is known to stop steroidogenesis $[45,60]$.

The cell type that is damaged is mainly in the early stage of spermatogenesis and the degree of germ cell damage is related to the dose of $\mathrm{Cd}$ exposure [9]. This is consistent with the current findings that the spermatogonia are the primary cells that are affected. In contrast, another researcher observed that the exfoliated sloughed germ cells were spermatocytes and spermatids [44].

Administration of $\mathrm{Cd}$ in the present study produced atrophy, vacuolations, cellular debris and the seminiferous epithelium was sloughed off at many points. These changes are consistent with the findings of the author who demonstrated that a single dose of $\mathrm{Cd}$ induced severe necrosis and degeneration of the seminiferous tubules with a complete loss of the centrally located spermatozoa [2].

In the current research, a wide interstitium and congested capillaries were noticed. Burukoğlu and Bayçu [10] observed several congested thickened blood vessels and homogeneous oedematous material in the interstitium which is infiltrated by different cells such as leukocytes and macrophages. The thickened blood vessel wall and oedema are due to cytokines secreted by macrophages situated in the peritubular zones $[1,44]$.

Ultrastructurally, the changes of the thickness of basal lamina observed in the present research could be explained by the study of Shokri et al. [50] who found that certain stimulants might encourage the myoid cells to yield more collagen and extracellular matrix, which cause the thickening of the basal lamina. 
In the current work, numerous intercellular areas were noticed in-between the germinal cells lining the seminiferous tubules. This is attributed to loosening of cell-cell connections and these gaps caused shrinkage of both germ and Sertoli cells [14]. A previous study observed disarrangement of germ cell structure and function that is due to elevated level of ROS in the membrane lipids $[16,56]$.

In $\mathrm{CdCl}_{2}$ treated group, Sertoli cells showed irregular euchromatic nuclei with variable damage of germ cells [23] and this agreed with the current findings. The present study revealed ultrastructural alteration of sperms as shown in the transverse sections of the mid-pieces of sperm that revealed disrupted axoneme and a distorted swollen mitochondrial sheath.

The mechanism of $\mathrm{Cd}$ induced injury involves the production of free radicals, which modify mitochondrial activity [13]. Therefore, other authors have postulated that antioxidants could be a critical aspect of the efficient management of $\mathrm{Cd}$ intoxication $[11,16]$.

Current work revealed that fenugreek administration reduces the unhealthy consequences of $\mathrm{Cd}$ on testicular tissues that are attributed to enhancement of antioxidant potential due to minimising lipid peroxidation [28]. Moreover, an experimental research demonstrated that consumption of herbal substance that contains polyphenols and flavonoids exerts antioxidant role and suppresses low density lipoprotein oxidation [55].

Some researchers have discussed the immunohistochemistry of the testicular architecture and they observed that macrophages and lymphocytes were limited around the basal lamina and in the interstitial spaces [32]. Other investigator observed that immune response infiltration of monoclonal antibodies for B- and T-lymphocytes and macrophages occasionally occurred in the lumen of the testes [26]. This is in accordance with our findings that CD68 immunoreactivity (macrophages) showed significant increase that is improved with the administration of combined fenugreek and $\alpha$-tocopherol. In the current study, CD20 showed significant increase in immunohistochemical positivity with $\mathrm{Cd}$ and this distinguishes cell injury, degeneration, inflammatory conditions and death of components of the testes [31]. A researcher noticed that crucial aetiological element responsible for male infertility is infection and inflammation of the epithelial tissue and suggested that T-lymphocytes participate in the regulation of male infertility pathogenesis [15].
A previous research suggests that fenugreek can be regarded a potential therapeutic nutrient to guard against male reproductive toxicity caused by $\mathrm{Cd}$ through its antioxidant, anti-inflammatory and antifibrotic actions [5].

A study using $\alpha$-tocopherol and $\mathrm{Cd}$ showed the seminiferous tubules and the Leydig cells almost retained their normal structure with normally arranged the seminiferous epithelium and a healthy interstitium [41]. Most of the mid-pieces of the sperm had a normal structure except a few of them showed distorted and swollen mitochondrial sheaths [41] and this agreed with the current findings.

Alpha-tocopherol has been found to minimise infections [8] and activate the adaptive immune system which was detected by the expression of Blymphocytes and T-lymphocytic surface antigens [36]. The antioxidant $\alpha$-tocopherol has also been found to be capable of diminishing apoptosis in degenerating cells of the testicular tissues [42]. Therefore, the role of $\alpha$-tocopherol can be defined as a defensive role for the testicular epithelium and lymphocytic system.

Our findings revealed that combined fenugreek and $\alpha$-tocopherol with $\mathrm{CdCl}_{2}$ decreases earlier structural alterations and reduces the injury and this coincides with the findings of a prior research [58]. The ameliorating effects of combined fenugreek and $\alpha$-tocopherol in the current work were slight and these results are consistent with the progression of alterations in the rat testes as a result of $\mathrm{Cd}$ intoxication explained by Sen Gupta et al. [47]. Alphatocopherol supplement has demonstrated fruitful effect in enhancing sperm quality [3]. This agreed with our suggestion that supplements of combined fenugreek and $\alpha$-tocopherol alleviates the oxidative stress. This regimen could re-establish the activity of antioxidant enzymes to allow regular germ cell differentiation and guard sperm count and protect testicular morphology throughout $\mathrm{Cd}$ exposure.

\section{Limitation of the study}

The limitations of the study are due to the small number of animals so, we advise to apply this study on a larger number of animals and different spices to facilitate the statistical analysis and to broaden the feedback. Also, we advise to apply different doses of the combination of fenugreek and $\alpha$-tocopherol. Quantitative measures as stereology are recommended to support the hypothesis of the study. 


\section{CONCLUSIONS}

The results obtained from the current study reveal that fenugreek and $\alpha$-tocopherol ameliorate histopathological variations of the testicular tissues created by $\mathrm{Cd}$ to some extent. These combined substances might be used as a dietary consumption of humans who are exposed to environmental toxins especially $\mathrm{Cd}$.

\section{ACKNOWLEDGEMENTS}

This work was funded by the Deanship of Scientific Research (DSR), King Abdulaziz University, Jeddah, Saudi Arabia under grant No. 140-219-D1435. The authors acknowledge the DSR technical and financial support with thanks.

\section{REFERENCES}

1. AbdAllah MA, Mohamed DA (2011) Histological study of the effect of experimentally induced unilateral torsion/ detorsion on testis of adult albino rats and role of rosuvastatin supplementation. Egyptian J Histol, 34: 436-447.

2. Abdollahi M, Bahreini-Moghadam A, Emami B, Fooladian F, Zafari K (2003) Increasing intracellular cAMP and cGMP inhibits cadmium-induced oxidative stress in rat submandibular saliva. Comp Biochem Physiol C Toxicol Pharmacol, 135C: 331-336.

3. Acharya UR, Mishra M, Patro J, Panda MK (2008) Effect of vitamins $C$ and $E$ on spermatogenesis in mice exposed to cadmium. Reproductive Toxicol, 25: 84-88.

4. Albasha MO, Azab SA (2014) Effect of cadmium on the liver and amelioration by aqueous extracts of fenugreek seeds, rosemary, and cinnamon in Guinea pigs: histological and biochemical study. Cell Biol, 2: 33- 34.

5. Arafa MH, Mohammad NS, Atteia HH (2014) Fenugreek seed powder mitigates cadmium-induced testicular damage and hepatotoxicity in male rats. Exp Toxicol Pathol, 66: 293-300.

6. Aslanturk A, Uzunhisarcikli M, Kalender S, Demir F (2014) Sodium selenite and vitamin $\mathrm{E}$ in preventing mercuric chloride induced renal toxicity in rats. Food Chem Toxicol, 70: 185-190.

7. Benoff SH, Millan C, Hurley IR, Napolitano B, Marmar JL (2004) Bilateral increased apoptosis and bilateral accumulation of cadmium in infertile men with left varicocele. Human Reproduction, 19: 616-627.

8. Berger MM, Chioléro RL (2007) Antioxidant supplementation in sepsis and systemic inflammatory response syndrome. Critical Care Med, 35: S584-S590.

9. Bu T, Mi Y, Zeng W, Zhang C (2011) Protective effect of quercetin on cadmium-induced oxidative toxicity on germ cells in male mice. Anat Rec (Hoboken), 294: 520-526.

10. Burukoğlu D, Bayçu C (2008) Protective effects of zinc on testes of cadmium-treated rats. Bulletin Environmental Contamination Toxicol, 81: 521-524.

11. Chionna A, Dwikat M, Panzarini E, Tenuzzo B, Carla E, Verri T, Pagliara P, Abbro L, Dini L (2009) Cell shape and plasma membrane alterations after static magnetic fields exposure. Eur J Histochem, 47: 299-308.
12. Colombo ML (2010) An update on vitamin $E$, tocopherol and tocotrienol-perspectives. Molecules, 15: 2103-2113.

13. de Burbure $C$, Buchet JP, Leroyer $A$, Nisse $C$, Haguenoer JM, Mutti A, Smerhovsky Z, Cikrt M, Trzcinka-Ochocka M, Razniewska G, Jakubowski M, Bernard A (2006) Renal and neurologic effects of cadmium, lead, mercury, and arsenic in children: evidence of early effects and multiple interactions at environmental exposure levels. Environ Health Perspect, 114: 584-590.

14. de Souza Predes F, Monteiro JC, Matta SL, Garcia MC, Dolder H (2011) Testicular histomorphometry and ultrastructure of rats treated with cadmium and Ginkgo biloba. Biol Trace Element Res, 140: 330-341.

15. Duan YG, Yu CF, Novak N, Bieber T, Zhu CH, Schuppe HC, Haidl G, Allam JP (2011) Immunodeviation towards a Th17 immune response associated with testicular damage in azoospermic men. Int J Androl, 34: e536-545.

16. El-Demerdash FM, Yousef MI, Kedwany FS, Baghdadi HH (2004) Cadmium-induced changes in lipid peroxidation, blood hematology, biochemical parameters and semen quality of male rats: protective role of vitamin $\mathrm{E}$ and beta-carotene. Food Chem Toxicol, 42: 1563-1571.

17. El-Shahat A, Gabr A, Meki AR, Mehana ES (2009) Altered testicular morphology and oxidative stress induced by cadmium in experimental rats and protective effect of simultaneous green tea extract. Int J Morphol, 27: 757-764.

18. Fang YZ, Yang S, Wu G (2002) Free radicals, antioxidants, and nutrition. Nutrition, 18: 872-879.

19. Farina M, Soares FA, Feoli A, Roehring C, Brusque AM, Rotta L, Perry ML, Souza DO, Rocha JB (2003) In vitro effects of selenite and mercuric chloride on liver thiobarbituric acid-reactive substances and non-protein thiols from rats: influences of dietary cholesterol and polyunsaturated and saturated fatty acids. Nutrition, 19: 531-535.

20. Flammang A, Cifone M, Erexson G, Stankowski L (2004) Genotoxicity testing of a fenugreek extract. Food Chem Toxicol, 42: 1769-1775.

21. Franke AA, Murphy SP, Lacey R, Custer $\amalg$ (2007) Tocopherol and tocotrienol levels of foods consumed in Hawaii. J Agricultural Food Chemistry, 55: 769-778.

22. Gupta RS, Gupta ES, Dhakal BK, Thakur AR, Ahnn J (2004) Vitamin $C$ and vitamin protect the rat testes from cadmium-induced reactive oxygen species. Mol Cells, 17: 132-139.

23. Haffor A, Abou-Tarboush F (2004) Testicular cellular toxicity of cadmium: transmission electron microscopy examination. J Environmental Biol/Academy Environmental Biol, India, 25: 251-258.

24. Heeba GH, Abd-Elghany MI (2010) Effect of combined administration of ginger (Zingiber officinale Roscoe) and atorvastatin on the liver of rats. Phytomedicine, 17: 1076-1081.

25. Israr M, Sahi S, Jain J (2006) Cadmium accumulation and antioxidative responses in the Sesbania drummondii callus. Arch Environmental Contamination Toxicol, 50: 121-127.

26. Jones C, St Jean S, Fréchette I, Bergeron D, Rivard N, Boudreau $F$ (2013) Identification of a novel promyelocytic leukemia zinc finger isoform required for colorectal cancer cell growth and survival. Int J Cancer, 133: 58-66.

27. Järup L, Åkesson A (2009) Current status of cadmium as an environmental health problem. Toxicol Applied Pharmacol, 238: 201-208. 
28. Kaviarasan S, Ramamurty N, Gunasekaran P, Varalakshmi E, Anuradha CV (2006) Fenugreek (Trigonella foenum graecum) seed extract prevents ethanol-induced toxicity and apoptosis in Chang liver cells. Alcohol Alcoholism, 41: 267-273.

29. Liu J, Qu W, Kadiiska MB (2009) Role of oxidative stress in cadmium toxicity and carcinogenesis. Toxicology Applied Pharmacol, 238: 209-214.

30. Lopez E, Arce C, Oset-Gasque M, Canadas S, Gonzalez M (2006) Cadmium induces reactive oxygen species generation and lipid peroxidation in cortical neurons in culture. Free Radical Biol Med, 40: 940-951.

31. Makita M, Murakami I, Yoshioka T, Tanaka H, Yamamoto K, Imajo K, Takata K, Yoshino T (2009) Extranodal CD20-positive peripheral T-cell lymphoma presenting with adrenal and testicular masses. [Rinsho ketsueki] Japanese J Clin Hematol, 50: 413-418.

32. Marchlewicz M (2000) Localization of immunocompetent cells in the human epididymis. Folia Histochemica et Cytobiologica, 39: 173-174.

33. Mehraein F, Negahdar F (2011) Morphometric evaluation of seminiferous tubules in aged mice testes after melatonin administration. Cell J, 13: 1-4.

34. Melo F, Matta SL, Paula TA, Gomes ML, Oliveira LC (2010) The effects of Tynnanthus fasciculatus (Bignoniaceae) infusion on testicular parenchyma of adult Wistar rats. Biological Res, 43: 445-450.

35. Monsefi M, Alaee S, Moradshahi A, Rohani L (2010) Cadmium-induced infertility in male mice. Environ Toxicol, 25: 94-102.

36. Morel $S$, Didierlaurent $A$, Bourguignon $P$, Delhaye $S$, Baras B, Jacob V, Planty C, Elouahabi A, Harvengt P, Carlsen H, Kielland A, Chomez P, Garcon N, Van Mechelen M (2011) Adjuvant System AS03 containing alpha-tocopherol modulates innate immune response and leads to improved adaptive immunity. Vaccine, 29: 2461-2473.

37. Mustafa HN (2012) Effect of acrylamide on testis of albino rats ultrastructure and DNA cytometry study. Saudi Medical J, 33: 722-731.

38. Mustafa HN, El Awdan SA, Hegazy GA (2013) Protective role of antioxidants on thioacetamide-induced acute hepatic encephalopathy: biochemical and Ultrastructural study. Tissue Cell, 45: 350-362.

39. Ognjanovic B, Markovic S, Pavlovic S, Zikic R, Stajn A, Saicic $Z$ (2008) Effect of chronic cadmium exposure on antioxidant defense system in some tissues of rats: protective effect of selenium. Physiological Res, 57: 403.

40. Ola-Mudathir KF, Suru SM, Fafunso MA, Obioha UE, Faremi TY (2008) Protective roles of onion and garlic extracts on cadmium-induced changes in sperm characteristics and testicular oxidative damage in rats. Food Chemical Toxicol, 46: 3604-3611.

41. Oliveira H, Spanò M, Santos C, Pereira ML (2009) Adverse effects of cadmium exposure on mouse sperm. Reproductive Toxicol, 28: 550-555.

42. Ramanathan K, Anusuyadevi M, Shila S, Panneerselvam C (2005) Ascorbic acid and alpha-tocopherol as potent modulators of apoptosis on arsenic induced toxicity in rats. Toxicol Letters, 156: 297-306.
43. Renugadevi J, Prabu SM (2009) Naringenin protects against cadmium-induced oxidative renal dysfunction in rats. Toxicology, 256: 128-134.

44. Rodriguez MG, Rival C, Theas MS, Lustig L (2006) Immunohistopathology of the contralateral testis of rats undergoing experimental torsion of the spermatic cord. Asian J Androl, 8: 576-583.

45. Sakr SA, El-Shenawy SM, Al-Shabka AM (2012) Aqueous fenugreek seed extract ameliorates adriamycin-induced cytotoxicity and testicular alterations in albino rats. Reprod Sciences, 19: 70-80.

46. Santos FW, Oro T, Zeni G, Rocha JB, do Nascimento PC, Nogueira CW (2004) Cadmium induced testicular damage and its response to administration of succimer and diphenyl diselenide in mice. Toxicol Letters, 152: 255-263.

47. Sen Gupta R, Sen Gupta E, Dhakal BK, Thakur AR, Ahnn J (2004) Vitamin C and vitamin E protect the rat testes from cadmium-induced reactive oxygen species. Mol Cells, 17: 132-139.

48. Sengupta P (2013) Environmental and occupational exposure of metals and their role in male reproductive functions. Drug Chemical Toxicol, 36: 353-368.

49. Sepaniak S, Forges T, Gerard H, Foliguet B, Bene MC, Monnier-Barbarino P (2006) The influence of cigarette smoking on human sperm quality and DNA fragmentation. Toxicology, 223: 54-60.

50. Shokri S, Hemadi M, Aitken RJ (2012) Transmission electron microscopy for the quantitative analysis of testis ultra structure. Transmission Electron Microscope, 113-126.

51. Shute T, Macfie SM (2006) Cadmium and zinc accumulation in soybean: a threat to food safety? Sci Total Environ, 371: 63-73.

52. Siu ER, Mruk DD, Porto CS, Cheng CY (2009) Cadmium-induced testicular injury. Toxicology Applied Pharmacol, 238: $240-249$

53. Smith M (2003) Therapeutic applications of fenugreek. Alternative Med Rev, 8: 20-27.

54. Suvarna SK, Layton C, Bancroft JD (2012) Bancroft's theory and practice of histological techniques, expert consult: online and print. 7th Ed. Churchill Livingstone, Elsevier Health Sciences.

55. Thirunavukkarasu V, Anuradha C, Viswanathan P (2003) Protective effect of fenugreek (Trigonella foenum graecum) seeds in experimental ethanol toxicity. Phytotherapy Res, 17: 737-743.

56. Thompson J, Bannigan J (2008) Cadmium: toxic effects on the reproductive system and the embryo. Reprod Toxicol, 25: 304-315.

57. Traber MG, Atkinson J (2007) Vitamin E, antioxidant and nothing more. Free Radical Biol Med, 43: 4-15.

58. Yang HS, Han DK, Kim JR, Sim JC (2006) Effects of alpha-tocopherol on cadmium-induced toxicity in rat testis and spermatogenesis. J Korean Med Sci, 21: 445-451.

59. Yu HN, Shen SR, Yin JJ (2007) Effects of metal ions, catechins, and their interactions on prostate cancer. Critical Rev Food Science Nutrition, 47: 711-719.

60. Zhang Q, Zou P, Zhan H, Zhang M, Zhang L, Ge RS, Huang $Y$ (2011) Dihydrolipoamide dehydrogenase and cAMP are associated with cadmium-mediated Leydig cell damage. Toxicol Letters, 205: 183-189. 